\title{
Research on the Evaluation Index System of Enterprise's Online Credit in B2C E-commerce
}

\author{
Fangkai Zhang ${ }^{1}$, Zhou Xu
}

${ }^{1,2}$ School of Economics and Management, Beihang University, Beijing, China

\begin{abstract}
Online reputation evaluation is a hot topic in e-commerce research. We analyses the existing problems of enterprise reputation evaluation in the current e-commerce environment from various views, then point out the influencing factors of enterprise online reputation in B2C e-commerce. By analyzing the influencing factors of enterprise reputation in $\mathrm{B} 2 \mathrm{C}$ e-commerce environment, we construct three dimensions: financial evaluation, user experience and potential evaluation. Finally, we establish an online reputation evaluation index system for enterprises in $\mathrm{B} 2 \mathrm{C}$ e-commerce environment.
\end{abstract}

Keywords: B2C E-Commerce, Online Reputation Evaluation, Index System

\section{Introduction}

With the rapid development of Internet, network consumption is increasingly respected by people, and Internet e-commerce, a new business operation mode, is gradually maturing. Compared with traditional business activities, there are more uncertainties in e-commerce. There is a stronger dependence on the trust relationship between the two sides of the transaction. Although many existing technologies make the transaction more secure, there is still a risk that the supplier will not comply with the use agreement, which is more prominent in $\mathrm{B} 2 \mathrm{C}$ transactions. Lack of trust has been repeatedly identified as one of the most formidable barriers to people for engaging in e-commerce 1. Under this circumstances, if an enterprise wants to obtain more market and profit, it must have good reputation evaluation, so that it can effectively win the initiative in market competition, increase sales and develop rapidly. The seller's reputation has an economically and statistically significant effect on price 2 .

Therefore, the study of an effective online reputation evaluation index system can provide a feasible and reliable scientific basis for building the trust environment of e-commerce, and help e-commerce develop healthily and rapidly.

\section{Problems in Online Transactions}

2.1 Information Asymmetry in Online Transactions

1) Business information asymmetry

The opening process of electronic stores is not standardized. In the $\mathrm{B} 2 \mathrm{C}$ e-commerce environment, there is no series of related registration in the office departments. Because it does not require too much investment cost, this makes the entry of electronic stores too low, and the information about the store are not enough. Only the merchants know their own situation, consumers know little, and there is no third-party organization to make a reliable guarantee of the quality and reputation of electronic stores. This makes the business information seriously asymmetric, and consumers are in a passive and disadvantaged position

\section{2) Asymmetric Information of Commodity Quality}

"Lemon theory" holds that buyers often have insufficient information about commodities, and merchants have information advantages 3 . It is easy to produce opportunistic behavior by utilizing this information advantage.

Compared with the traditional face-to-face commodity trading, consumers can only see what they want to buy through electronic data in the e-commerce environment. The way of displaying commodities is pictures, words or "seller's show". There is no guarantee of authenticity for the pictures or words displayed in front of consumers. When consumers are not aware of the seller's reputation, it is very likely that the description of the goods will be totally inconsistent with that they receive from the merchants. Such information on the quality of the goods is completely asymmetric, which makes the rights and interests of consumers unprotected.

\section{3) Adverse Selection}

In the environment of e-commerce, the existing information of consumers and businesses is seriously asymmetric. When consumers can't judge whether a product is good or not, they tend to focus on products with cheaper prices, because at least in this way they spend less money, even if they are deceived, they won't lose much. In this way, in order to gain more market benefits, the merchants who really have quality 
assurance begin to sell inferior products. Slowly, inferior products occupy the whole market. This is the phenomenon of "inferior currency expels good currency" mentioned in monetary banking. It hits the efficiency of the whole market. The interests of businesses and consumers can't be guaranteed.

\subsection{Payment Credit Problem in Online Transaction}

Transaction settlement in e-commerce environment is also a place prone to credit problems. Businessmen and consumers have their own concerns about transactions. Katsaros et al. pointed out that payment systems play a vital role in modern e-commerce 4.

In the online virtual environment, consumers can't see physical objects, and the consumers' off-line shopping habits are changed. It will generate more distrust, and businesses will worry about not receiving money. In addition, with the upgrading of payment methods, fraudulent means are also upgrading. Sometimes consumers will encounter false orders or false consumption, which makes consumers feel insecure.

\subsection{Integrity in Online Transaction}

1) Delay in delivery and non-fulfilment of service commitments

Although online shopping sellers have tool a lot of work into the description of goods, the service stage still needs to be improved. In the actual trading, logistics is also a part of consumers' concern, and logistics service is also an important aspect for enterprises to obtain customer satisfaction.

2) The Problem of Credit Supervision Mechanism Online shopping only need sellers to provide copies of identity cards and bank card numbers. There is no mandatory regulatory unit, nor a third-party guarantee unit. For customers who visit sellers without any credit records for the first time, their consumption risk increases, so it is necessary to improve the integrity supervision mechanism and make a basic reputation evaluation for the information of enterprises.

3) Imperfect evaluation system

Jiang pointed out that there are many malicious acts in online transaction 5. A reputation system can assist other parties in deciding whether or not to transact with that party in the future 6. A trust and reputation mechanism has more advantages in solving the selection problem for web services 7. But it is not perfect now. As far as our well-known JD is concerned, after completing a complete transaction, consumers can evaluate the reputation of the merchants. There are some problems. If users do not make ratings within the prescribed time limit, the system will automatically default to "praise", so there will be a lot of inferior goods as good goods. Under such a credit evaluation mechanism, in order to improve their credibility, many merchants hire others to brush out good reviews, which largely destroy the online trading environment.
4) The evaluation grade is too simple

Lee pointed out that the scores and reviews obtained by sellers in online transactions are important basis for buyers to identify the quality of sellers' products 8 . However, consumers with online shopping experience will know that there are only three levels in the evaluation after the completion of the transaction, namely "good", "medium" and "poor". The demarcation between the levels is too vague, it is difficult to accurately distinguish the true evaluation of users, and the evaluation mechanism is not perfect.

Therefore, with the moral deficiencies and information asymmetry in online transactions, the role of online reputation has been paid more and more attention by various trading entities. Resnick points out that the effective way to reduce the fraud rate in online transactions is to design a reputation feedback mechanism 9. It provides an incentive for good behavior. Dholakia believes that credit management systems can help consumers differentiate different businesses according to their credibility 10. Online reputation plays an important role in establishing a good online trust relationship between the two parties. There are much benefits to study online reputation evaluation system for enterprises. Firstly, enterprises are willing to manage and maintain their online reputation subjectively. Secondly, enterprises hope that their products and services can meet the needs of consumers. Finally, good online reputation of enterprises can be guaranteed.

\section{Factor Analysis of Enterprise's Online Credit in B2C E-Commerce}

Ye and Henry starts with the e-commerce shopping environment, they studied the design of e-commerce website. Then they analyzed the influence of different content, style and interactive experience on online reputation and studied the influencing factors of online reputation from more perspectives, pointing out that whether businesses can satisfy consumers, the privacy of shopping environment and the logistics services of businesses are the three main influencing factors of online reputation 11 . Referring to previous studies, we divide online reputation impact factors into two aspects: enterprise traditional inherent factors and factors under e-commerce.

\subsection{Enterprise traditional Inherent Factor \\ 3.1.1 Factor Analysis of Enterprise External Environmental Impact}

1) Macro environment.

The operation and development of enterprises are often affected by the macro environment, even if it does not directly affect the activities of enterprises. It mainly includes three aspects: politics, economy and culture. The political aspect mainly refers to the influence of the state or region's political policies and laws and regulations. The economic aspect refers to the objective factors such as the social and economic environment in 
which the enterprise is currently located, such as the impact of the financial crisis. The cultural aspect refers to the local culture where the enterprise is located, including the influence of cultural customs, religious beliefs, social traditions and so on.

2) Industry.

Mainly on the industry development status, industry development potential, industry competitors, market demand, etc.

3) Business environment.

It is mainly about the market competition faced by enterprises.

\subsubsection{Factor Analysis of Enterprise's Self-influence}

Enterprise's own influence factors involve human, financial, material and other aspects of the enterprise. Including: (1) the scale and economic strength of enterprises. (2) the basic situation of employees, that is, the quantity and quality of personnel. (3) the enterprise management ability. Mainly includes the management quality judgment of enterprise managers, enterprise culture and development strategy. (4) Analysis of enterprise equipment capability. Including the advanced equipment owned by enterprises, which is another aspect to reflect the innovative ability of enterprises. (5) Research and development capabilities, including high-tech talents, high-tech equipment and $R \& D$ investment of enterprises. (6) Financial ability, $n$ our usual understanding, the more powerful the financial resources of enterprises, the more trustworthy.

\subsubsection{Corporate Social Responsibility}

In recent years, the social responsibility of small and medium-sized enterprises is also increasing. Many small and medium-sized enterprises have joined the annual ranking activities of social responsibility reports. Many third-party organizations also have relevant corporate social responsibility evaluation projects. Enterprises should not blindly abandon the protection of human rights and the protection of the environment for the sake of economic interests and profits. They should take a longer-term view and care about maximizing the return of capital.

\subsubsection{Other influencing factors}

Mainly includes the past solvency and credibility and other factors. Such as available bank loan indicators, past solvency and past credit, etc.

\subsection{Increasing factors in e-commerce environment}

1) Products and prices

The quality and price of products are the most concern of consumers. In today's active e-commerce, consumers can compare many products on the Internet without leaving home, and ultimately select the products with the highest selective price ratio for purchase. On the one hand, enterprises must ensure the quality of products on the line, on the other hand, they should set reasonable pricing according to the user groups facing the products. They can't blindly reduce the quality level of products in order to pursue the order quantity. They always fight low-price battles to ensure that they can win a greater victory in the consumer battle of e-commerce.

\section{2) Service-related}

Whether the promises given by enterprises to consumers can be fulfilled is an important factor affecting the reputation of enterprises in terms of services, such as unreasonable return of goods within a certain period of time, whether the genuine products are correct, whether the invoice certificate is available, and so on. At the same time, the interaction between enterprises and consumers, including timely manual consultation before, during and after purchase, is also an important aspect of consumers' perception of corporate services. Consumers hope that they can solve all problems at any time, which requires the enterprise's customer service as full-time online as possible, in order to get more customers' favor and increase the reputation value.

\section{3) Logistics-related}

In logistics related services, there are mainly several aspects that affect online reputation: the first is the speed of logistics distribution. Fast distribution will bring consumers a better customer experience; the second is the quality assurance of logistics. In the process of logistics distribution, the integrity and freshness of goods should be maintained; the third is the tracking of logistics information. With the rapid development of information technology, whether consumers can track the real-time logistics information of the goods they sell on the Internet, also has a great impact on consumer experience; the fourth is logistics service personnel. Consumers' perception of service level of courier in e-commerce will also affect online reputation. Logistics service has a greater impact on online reputation. At present, more and more B2C merchants realize the importance of logistics and begin to build their own logistics system and develop the whole industry chain, which will affect the online reputation of enterprises to a greater extent.

4) Web Platform Relevance

The main role in the development of e-commerce is not only the seller and buyer, but also the third-party platform. The role of third-party platform is to link buyers and sellers, provide information display of merchants, consumers, commodities and logistics, and provide payment and transaction interface. It plays a decisive role in the development mode of e-commerce, so it also has a decisive influence on online reputation. Specifically, it mainly embodies in the aspects of website security, website usability, website reliability and so on.

4. Evaluation Index Analysis of Business Credit in B2C 


\section{Electronic Commerce}

At this stage, many scholars have studied the factors affecting online reputation of $\mathrm{B} 2 \mathrm{C}$ e-commerce according to different subjects and modes, but there are few comprehensive studies. In combination with the main aspects of the impact factors of B2C e-commerce in the previous paper and the main domestic research papers on online impact factors, we summarize the impact indicators of enterprise online reputation in $\mathrm{B} 2 \mathrm{C}$ e-commerce environment.

Based on the analysis of literature and the combination of the same or similar impact factors, we divide the impact indicators of online reputation of enterprises in B2C e-commerce into three major aspects: financial correlation, user experience correlation and enterprise development potential. The thinning factors corresponding to the direction of the three dimensions are shown in Table. 1.

Table 1. The Corresponding Relation between Indicators and Influencing Factors

\begin{tabular}{ll|ll|l}
\hline Financial related & User Experience related & Enterprise Development Potential \\
\hline$\bullet$ & $\begin{array}{l}\text { External Environmental Impact } \\
\text { of Enterprises } \\
\text { intrinsic Impact of Enterprises }\end{array}$ & $\bullet \begin{array}{l}\text { Products and Prices, Services, } \\
\text { Logistics }\end{array}$ & Social Responsibility \\
Website platform & & \\
\hline
\end{tabular}

Through literature analysis, the same or similar impact factors and indicators are merged, and some impact factors are quasi-quantitatively processed to integrate the online reputation impact factor index system.

4.1 Financial Evaluation Index

The financial index system of online reputation in e-commerce environment, from the comprehensive analysis of the impact factors, we find that the general data mainly come from balance sheet and profit statement. That means the financial ability largely depends on the net profit of the enterprise. We add cash flow statement based on cash to judge the ability of enterprises to obtain profits. It is formulated from three aspects: profitability, solvency and operation ability. The finally determined indicators are shown in Table 2:

Table 2. Financial evaluation index

\begin{tabular}{|c|c|c|}
\hline First level index & Two level index & Three level index \\
\hline \multirow{15}{*}{$\begin{array}{c}\text { Financial Evaluation Index } \\
\text { of Enterprise's Online Credit } \\
\text { under B2C E-commerce } \\
\text { Environment }\end{array}$} & \multirow[t]{4}{*}{ Profitability (A) } & Sales profit margin (A1) \\
\hline & & Return on net assets (A2) \\
\hline & & Return on total assets(A3) \\
\hline & & Cash withdrawal ratio (A4) \\
\hline & \multirow[t]{7}{*}{ Solvency (B) } & Asset-liability ratio (B1) \\
\hline & & Quick ratio(B2) \\
\hline & & Liquidity ratio (B3) \\
\hline & & Guaranteed multiple of earned \\
\hline & & Cash flow ratio(B5) \\
\hline & & Cash maturity liability ratio (B6) \\
\hline & & Total cash liabilities B7 \\
\hline & \multirow[t]{4}{*}{ Operational capability (C) } & Receivable turnover rate $(\mathrm{C} 1)$ \\
\hline & & Inventory turnover $(\mathrm{C} 2)$ \\
\hline & & Total asset turnover rate (C3) \\
\hline & & Cash Purchase-Sale Ratio(C4) \\
\hline
\end{tabular}

4.2 User Experience Indicators

Since users give user experience evaluation after each consumption, the evaluation system should be as concise and comprehensive as possible, and it can be concluded whether users are satisfied with the consumption. According to the impact factors and sub-indicators in the e-commerce environment analyzed above, the first-level indicators of user experience evaluation for $\mathrm{B} 2 \mathrm{C}$ e-commerce enterprises are established, which include three aspects: website experience, product experience and service. Each sub-index is subdivided, and these main indicators are subdivided, such as Table 3.

Table 3. User Experience Indicators

\begin{tabular}{c|c|c}
\hline First level index & Two level index & Three level index \\
\hline Evaluation Index of & Website experience(A) & Safety(A1) \\
\cline { 2 - 2 } Enterprise Online Credit & & Reliability(A2) \\
\cline { 2 - 2 } User Satisfaction in & & Ease of use(A3) \\
\cline { 3 - 3 } B2C E-commerce & Product experience(B) & Individualization(B1) \\
\cline { 3 - 3 } Environment & & Quality(B2) \\
\cline { 3 - 3 } & & Product information(B3) \\
\cline { 3 - 3 } & Service experience(C) & Service attitude(C1) \\
\cline { 3 - 3 } & & Service information(C2) \\
\cline { 3 - 3 } & & payment(C3) \\
\cline { 3 - 3 } & & Delivery(C4) \\
& & Communication and Feedback(C5) \\
\hline
\end{tabular}


4.3 Potential Evaluation Index

Under the environment of e-commerce, the construction of online reputation potential evaluation index of $\mathrm{B} 2 \mathrm{C}$ enterprises, taking into account the general business conditions and personnel development, along with the development of social and moral factors such as green development and employee care, has also joined the current social contribution ability. Mainly from five aspects: personnel quality, innovative $R \& D$ ability, social contribution ability, market development ability and brand influence ability, such as Table 4 .

Table 4. Potential evaluation index

\begin{tabular}{|c|c|c|}
\hline First level index & Two level index & Three level index \\
\hline \multirow{14}{*}{$\begin{array}{l}\text { Index of Enterprise's Online } \\
\text { Credit Potential under B2C } \\
\text { E-commerce Environment }\end{array}$} & \multirow[t]{3}{*}{ Quality of personnel(A) } & $\begin{array}{c}\text { Educational background of } \\
\text { managers(A1) }\end{array}$ \\
\hline & & Manager industry experience (A2) \\
\hline & & Employee education(A3) \\
\hline & \multirow[t]{3}{*}{ Capability of innovative R\&D (B) } & $\mathrm{R} \& \mathrm{D}$ expenses(B1) \\
\hline & & Growth rate of technology input(B2) \\
\hline & & $\begin{array}{l}\text { Net interest rate on new product } \\
\text { sales(B3) }\end{array}$ \\
\hline & \multirow{4}{*}{$\begin{array}{l}\text { Capability of social contribution } \\
\text { (C) }\end{array}$} & Employee Wage Growth Rate(C1) \\
\hline & & Social Security Payment Rate(C2) \\
\hline & & Human capital input rate(C3) \\
\hline & & Social contribution rate $(\mathrm{C} 4)$ \\
\hline & \multirow{2}{*}{$\begin{array}{c}\text { Capability of market } \\
\text { development(D) }\end{array}$} & Sales growth rate(D1) \\
\hline & & Gross Asset Growth Rate(D2) \\
\hline & \multirow[t]{2}{*}{ Capability of brand influence (E) } & Brand awareness(E1) \\
\hline & & Brand reputation(E2) \\
\hline
\end{tabular}

\section{Conclusion}

We analyze the factors that affect the reputation of enterprises through the analysis of the inherent factors of enterprises and the factors that increase in the environment of e-commerce. Then, through the method of literature analysis, we extract the impact factors and part of the index system of online reputation of enterprises. Finally, we classify all the factors and match the evaluation indicators of three dimensions (finance, user experience, development potential) with different factors.

Enterprises or related organizations can incorporate these evaluation indicators into the evaluation system and adopt appropriate evaluation methods to obtain more credible evaluation results.

\section{Acknowledgment}

This research is supported by the National Key Research and Development Plan (Grant No.2016YFF0202604 and No.2017YFF0209604), the National Key R\&D Program of China (No. 2018YFC0807500).

\section{Reference}

1. Wang Y D. An overview of online trust: concepts, elements, and implications [J]. Computer in Human Behavior, 2014, (11): $1-21$

2. Houser D, Wooders J. Reputation in internet auctions: theory and evidence from eBay[J]. Journal of Economics and Management Strategy, 2006, 15(2):353-369.

3. Houston, J.H \& R.w.spencer, Quality, uncertainty and the Internet: the market for cyber lemon[J], American Economist, 2002,46(1):51-62

4. Katsaros P. A roadmap to electronic payment transaction guarantees and a Colored Petri Net model checking approach $[\mathrm{J}]$. Information and Software Technology, 2009, 51(2):235-257

5. Jiang W J, Xu Y S, Guo H, et al. Multi agent system-based dynamic trust calculation model and credit management mechanism of online trading[C]. International Conference on Human Centered Computing. Springer, Cham, 2014: 168-181.

6. Jøsang A, Ismail R, Boyd C. A survey of trust and reputation systems for online service provision[J]. Decision support systems, 2007, 43(2): 618-644.

7. Wang Y, Vassileva J. A review on trust and reputation for web service selection[C].The 27th International Conference on Distributed Computing Systems Workshops (ICDCSW'07). IEEE, 2007: 25-25.

8. Ang, Dubelaar, Lee. To trust or not to trust? a model of internet trust from the customer point of view[C]. the 14th Bled Electronic Commerce Conference. Bled: Republic of Electronic Commerce, 2001: 569-578.

9. Resnick P, Kuwabara K , Zeckha user R , et al. Reputation System s[ J] . Communications of the ACM , 2000, 43( 12) : 45-58.

10. Dholakia U M, The usefulness of bidders reputation ratings to sellers in online actions[J]. Journal of Interactive Marking, 2015, 19(1):31 - 40.

11. Ye Diana Wang, Henry H. Emurian (2005). An overview of online trust: Concepts, elements, and implications, Computers in Human Behavior, Volume 21, Issue 1. 